\title{
O comportamento dos docentes estrangeiros da Universidade Federal do Ceará
}

\section{no âmbito da autogestão de carreira}

\author{
The behavior of foreign professors at the Federal University of Ceará within the scope of career \\ self-management
}

El comportamiento de los profesores extranjeros en la Universidad Federal de Ceará en el ámbito de la autogestión profesional

José César Pontes Moreira

ORCID: https://orcid.org/0000-0002-7114-8817 Universidade Federal do Ceará, Brasil E-mail: cesarpontes@ufc.br

Karen Rachel Santos Clark

ORCID: https://orcid.org/0000-0003-0308-4003 Universidade Federal do Ceará, Brasil E-mail: karen@ufc.br José Rogério Santana

ORCID: https://orcid.org/0000-0002-8327-5864 Universidade Federal do Ceará, Brasil E-mail: rogersantana@ufc.br

Antônio Roberto Xavier

ORCID: https://orcid.org/0000-0002-3018-2058 Universidade da Integração Internacional da Lusofonia Afro-Brasileira, Brasil E-mail: roberto@unilab.edu.br

Marcos Antônio Martins Lima

ORCID: https://orcid.org/0000-0001-5541-6220 Universidade Federal do Ceará, Brasil E-mail: marcos.a.lima@terra.com.br

\begin{abstract}
Resumo
O objetivo deste trabalho é identificar e analisar os comportamentos dos docentes estrangeiros da Universidade Federal do Ceará em relação à autogestão de carreira, considerando o modelo teórico de autogestão da carreira de King (2004), os tipos de Comportamento de Posicionamento, Influência e Gestão dos Limites Trabalho-Vida Pessoal de alguns professores foram caracterizados. Esta pesquisa adotou uma abordagem qualitativa, interpretativa, realizada por meio de entrevistas semiestruturadas com 13 professores estrangeiros atuantes na Universidade Federal do Ceará. Os dados primários foram tratados através de análise de conteúdo, utilizando o software Atlas TI. Os resultados apontaram que o Comportamento de Posicionamento preponderante se refere à inovação do conteúdo do trabalho; os principais Comportamentos de Influência adotados são a autopromoção e a influência ascendente; e a Gestão dos Limites Trabalho-Vida Pessoal é administrada satisfatoriamente pelos docentes estrangeiros da Universidade Federal do Ceará.
\end{abstract}

Palavras-chave: Ensino; Pessoal; Comportamento; Desenvolvimento profissional.

\begin{abstract}
The objective of this work is to identify and analyze the behaviors of foreign professors from Federal University of Ceará in relation to careers self-management, considering King's theoretical model of self-management of career (2004), the types of Behavior of Positioning, Influence and Boundary Management (work-life limits) of these professors were characterized. This research had a qualitative, interpretative approach, carried out through semistructured interviews with 13 effective foreign professors working at Federal University of Ceará. In relation to the primary data, these were treated through content analysis, using Atlas TI software. The results pointed out that their prevailing Positioning Behavior refers to the innovation of the content of the work; the main Behaviors of Influence adopted by them are self-promotion and ascendant influence; and the Management of Work-Life Limits is managed satisfactorily by foreign professors at the Federal University of Ceará.
\end{abstract}

Keywords: Teaching; Folks; Behavior; Professional development. 


\begin{abstract}
Resumen
El objetivo de este trabajo es identificar y analizar el comportamento de los professores extranjeros de la Universidad Federal de Ceará em relación con la autogestión de carrera, considerando el modelo teórico de autogestión de carrera de King (2004), se caracterizaron los tipos de Conducta de Posicionamiento, Influencia y Gestión de los Limites VidaTrabajo de algunos docentes. Esta investigación adoptó um enfoque interpretativo cualitativo, realizado através de entrevistas semiestructuradas con 13 profesores extranjeros que trabajan en la Universidad Federal de Ceará. Los datos primarios se trataron mediante análises de contenido, utilizando el software Atlas TI. Los resultados mostraron que el comportamento de posicionamiento predominante se refiere a la innovación del contenido del trabajo; los principales comportamentos de influencia adoptados son la autopromoción y la influencia ascendente; y la Gestión de Límites Vida Laboral es administrada satisfactoriamente por profesores extranjeros de la Universidad Federal de Ceará.
\end{abstract}

Palabras clave: Ensenãnza; Personal; Comportamiento; Desarollo profesional.

\title{
1. Introdução
}

A Autogestão de Carreira tem sido uma temática investigada com interesse pela academia, haja vista sua relevância para todos os trabalhadores na atualidade. Seu estudo procede também de uma constatação intuitiva: o fato de a gestão da carreira ser hoje uma responsabilidade de empregados proativos e flexíveis, o que antes era eminentemente da alçada das organizações (Raabe; Frese; Beehr, 2007).

O modelo taylorista-fordista de organização precisou se atualizar ante os sistemas emergentes de produção e consumo (Fraser; Hvolby, 2010). Os novos paradigmas desses sistemas demandavam inovações tecnológicas e diversificadas modalidades administrativas, as quais foram implementadas em escala mundial desde o último quarto do século XX (Luna, 2012). Seligmann-Silva et al. (2010) alertam para o fato de que muitos desses fatores contribuíram para uma precarização social. Diante disso, inevitavelmente, organizações, com ou sem fins lucrativos, governos e pessoas precisaram se ajustar às demandas desses novos sistemas de produção.

Acrescentem-se a essa realidade os novos desafios gerados pela globalização. É, então, natural que o contexto social, econômico e político pelo qual a sociedade transita, em seus intercâmbios com a academia, afete e seja afetado nessas interações. Selmer e Lauring (2013) apontam, inclusive, o aumento da incidência de instituições de ensino no mercado global interessadas na captação de talentos estrangeiros, embora, em muitos casos, a iniciativa de ingresso na instituição estrangeira parta do acadêmico interessado na mudança.

Jacob (2015, p. 3 apud Farina; Penof, 2020, p. 130) argumenta que "[...] pesquisadores de várias origens e áreas de especialização mostram a vantagem de uma abordagem interdisciplinar para resolução de problemas". Os docentes estrangeiros são colaboradores para a articulação e internacionalização das universidades e para a criação de um ambiente criativo. Borba et al. (2020, p. 33) pontuam que se "[...] faz necessário um novo modelo de ambiente que fomente o conhecimento e a geração de ideias inovadoras capazes de contribuir ativamente no desenvolvimento da sociedade".

A Universidade Federal do Ceará (UFC), sendo uma autarquia vinculada ao Ministério da Educação (MEC), contrata profissionais para o quadro efetivo do Magistério Superior por meio de concurso público (Brasil, 2012). Semelhantemente, a contratação de professores substitutos e visitantes é realizada por meio de processo seletivo específico e é considerada, pela lei, uma medida para suprir a falta de docentes efetivos, nos casos de exoneração ou demissão, falecimento, aposentadoria, afastamento ou licença (Brasil, 2011).

Os docentes que ingressam no quadro efetivo da UFC entram, geralmente, com o título de doutor em sua área de conhecimento, iniciando a atuação profissional no regime de dedicação exclusiva (40 horas semanais). Além da expertise técnica, medida nas provas de escrita e nos títulos, a didática dos candidatos é também avaliada em uma aula de teste.

A categoria dos docentes estrangeiros - que desde 1934 (Unesco, 2002) contribui para o ensino e a pesquisa de nível superior em solo brasileiro - merece atenção especial. Por meio de seu olhar diferenciado, das experiências pessoais e de trabalho, novas perspectivas podem ser ponderadas para o melhoramento das práticas administrativas, de ensino, de pesquisa e 
de extensão na UFC. Inclusive, convém ressaltar que, desde 2016, um dos focos atuais de ação da UFC ocorre no sentido de incrementar seu nível de internacionalização (UFC, 2016, 2017). Discute-se sobre maneiras de expandir as alianças e os contatos com os centros universitários do mundo inteiro, de atrair mais estudantes internacionais como também mais docentes estrangeiros.

Para embasar este trabalho, escolheu-se estudar as escolhas dos docentes estrangeiros da UFC às dimensões Comportamento de Posicionamento, Comportamento de Influência e Gestão de Limites Trabalho-Vida Pessoal, conforme a teoria de King (2004). Esses três componentes são referentes ao modelo teórico "Autogestão de Carreira", da pesquisadora britânica Zella King (2004). São comportamentos que visam a moldar o curso da carreira em prol de resultados almejados de carreira.

A Figura 1 abaixo, apresenta o fluxo da autogestão de carreira, onde se percebe que a consecução dos resultados almejados resulta em satisfação na vida ou/e satisfação na carreira e/ou impotência. Nesse esquema, a pessoa pode alcançar uma das satisfações juntas ou separadamente. A impotência é consequência dos resultados de carreira não alcançados, onde a pessoa tem o sentimento de não ter a competência para autogerir a carreira.

Figura 1 - Modelo teórico da Autogestão de Carreira.

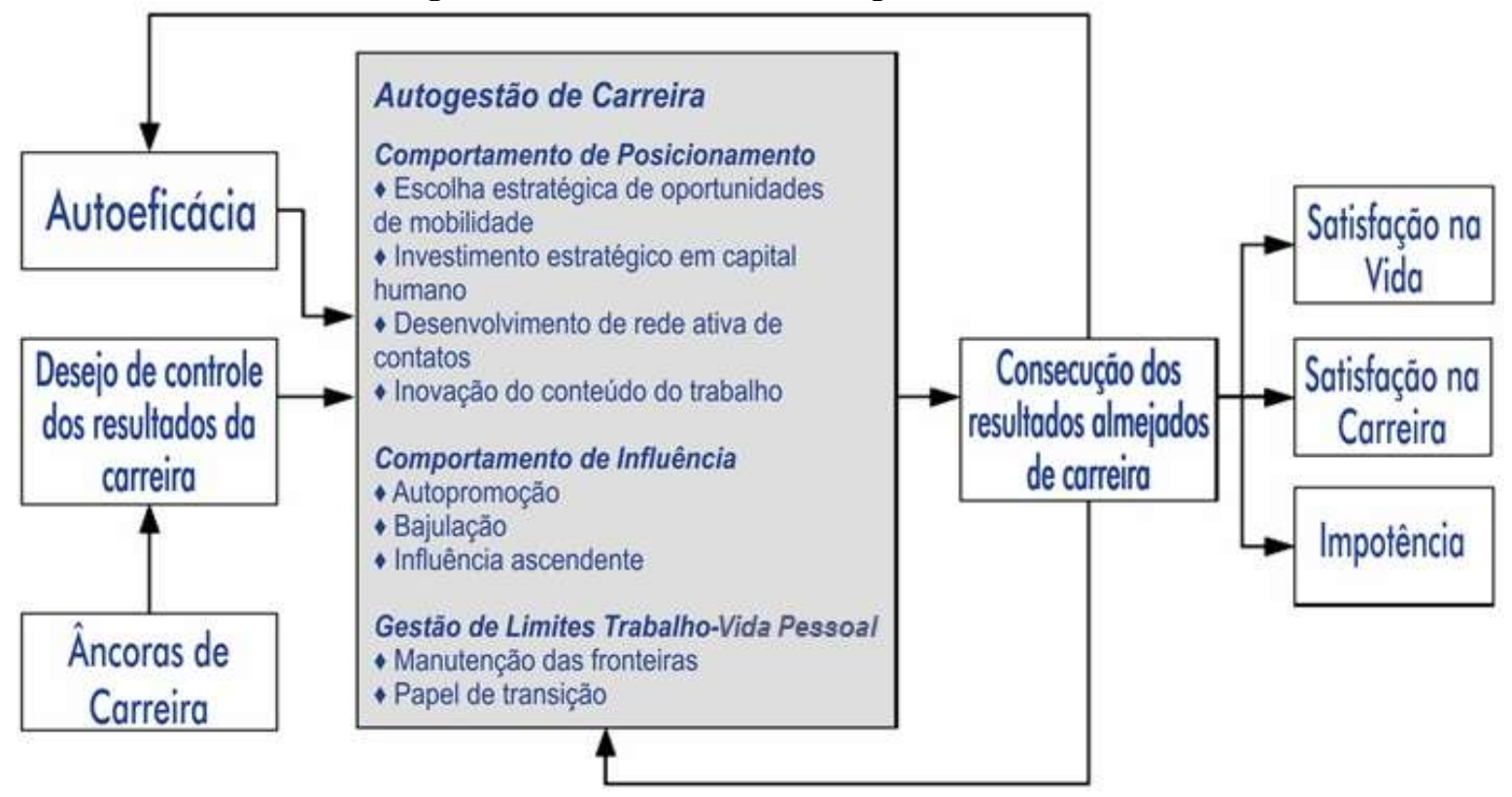

Fonte: King (2004).

Conforme enfatizado por King (2004), o cerne da Autogestão de Carreira refere-se à proatividade que cada um deve desenvolver em relação ao curso de sua vida profissional. Ainda que as organizações possam oferecer vantagens que sejam atraentes para os trabalhadores, a estes cabe a responsabilidade por seu desenvolvimento, por sua competitividade profissional e pelo curso de sua carreira (Veloso; Dutra; Nakata, 2016).

$\mathrm{Na}$ pressuposição de que os trabalhadores não têm ingerência plena sobre os resultados pretendidos para as suas carreiras, tais como progressão salarial, desenvolvimento de habilidades, renovação de contrato ou redução de horas de trabalho, King (2004) atesta que esses aspectos são controlados por aqueles que se encontram em posições de chefia. São chefias imediatas, executivos, profissionais de Recursos Humanos (RH) que influenciam as etapas de ascensão ou melhorias de uma carreira, sendo chamados de "porteiros" (King, 2001).

Da perspectiva dos trabalhadores, é sempre interessante identificar os "porteiros" relacionados à sua carreira, ou seja, aqueles que têm uma influência no controle atual ou futuro das etapas desejadas de desenvolvimento (King, 2004). Em 
situações de planejamento de mudança na carreira, os "porteiros" visados seriam aqueles que se referem aos postos futuros, e não exatamente aos superiores do emprego atual.

Os "porteiros" também são um aspecto importante a se considerar quando se analisa o capital humano. É preciso identificar que habilidades ou experiências são valorizadas por esses decisores, a fim de que a pessoa possa alinhar suas escolhas de autodesenvolvimento em função desse fator (King, 2004). Nos casos de futuras contratações, os trabalhadores buscam tornar seus currículos mais interessantes em função dos critérios imaginados como atraentes para esses "porteiros".

A teoria de King (2004) contempla também o antes e o depois da Autogestão de Carreira. O antes diz respeito às suas causas, ou seja, àqueles fatores que propulsionam a proatividade sobre os caminhos profissionais. As causas mais relevantes são: a noção de autoeficácia, a qual Newstrom (2008) define como a crença interna de que se tem as capacidades e competências necessárias à execução do trabalho, e o desejo de controle sobre a carreira se manifesta por meio da preocupação quanto aos resultados almejados da carreira. Este desejo está amparado nas âncoras de carreira propostas por Schein (2013), as quais designam áreas de competência, motivações e valores que norteiam as decisões relacionadas à esfera profissional.

São oito categorias principais: Competência Técnico-Funcional (capacidade de se atingir uma performance à altura dos padrões requeridos pelos contratadores no contexto do trabalho); Competência Administrativa Geral (responsabilidade de integrar os esforços de um time em prol de resultados específicos); Autonomia/Independência (necessidade inerente de se realizar o trabalho de um modo que seja no ritmo que a pessoa queira); Segurança/Estabilidade (tem como pilares a segurança financeira, a estabilidade no emprego e até a estabilidade geográfica); Criatividade Empresarial; Serviço/Dedicação a uma Causa; Desafio Puro (com elementos de novidade, variedade e dificuldade); e Estilo de Vida (maior preocupação é balancear as demandas de trabalho com os contextos fora dele, como família e hobbies de predileção).

Conforme preconizado por King (2004), a Autogestão de Carreira é efetuada por meio dos comportamentos adotados pelos trabalhadores, os quais são divididos em três grupos: Comportamentos de Posicionamento; de Influência; e de Gestão de Limites Trabalho-Vida Pessoal. Os Comportamentos de Posicionamento são aqueles voltados à aquisição de contatos, habilidades e experiências que viabilizarão alguns resultados pretendidos de carreira; os Comportamentos de Influência estão dirigidos diretamente a influenciar as decisões dos "porteiros", com vistas à obtenção dos resultados pretendidos de carreira, tais como autopromoção e bajulação; e a Gestão de Limites Trabalho-Vida Pessoal se concentra no equilíbrio das exigências do trabalho em contraposição às demandas provenientes de contextos de fora dele.

São quatro os comportamentos de Posicionamento listados por King (2004): escolha estratégica de oportunidade de mobilidade (quando se aceitam ou se rejeitam alterações no curso da carreira propostas pela chefia/organização, como mudanças de cidade ou lotação em cargos diferentes); investimento estratégico em capital humano (investimentos diretos em treinamentos e qualificações profissionais); desenvolvimento de uma rede ativa de contatos; e inovação do conteúdo do trabalho (mudanças cruciais em termos de métodos ou procedimentos no exercício de determinadas tarefas).

Os Comportamentos de Influência são manifestados de três maneiras: autopromoção (destaque de desempenho perante suas chefias objetivando causar uma impressão positiva); bajulação (esforço empregado para provocar mais simpatia e apreço nas chefias pelo trabalhador); e influência ascendente (negociação e barganha de melhorias com as chefias).

Quanto à Gestão de Limites Trabalho-Vida Pessoal (King, 2004), seriam dois os comportamentos específicos dessa categoria: manutenção das fronteiras (nível de separação das atividades do domínio do trabalho em relação às questões do domínio pessoal, como família e amigos); e papéis de transição (atitudes que facilitam a passagem entre os domínios, por exemplo, ler jornais ou e-mails no café da manhã).

King (2004) resumiu em três os fatores de consequências de carreira, ou seja, o "depois" da Autogestão de Carreira: satisfação na vida, satisfação na carreira e impotência. A satisfação na vida poderá advir de uma percepção de equilíbrio entre 
trabalho e vida pessoal. A satisfação na carreira enfatiza a análise positiva dos aspectos profissionais. E o sentimento de impotência refere-se à percepção desagradável de fracasso e não ajustamento à carreira ou profissão.

Para fins deste estudo, o objetivo geral propôs identificar e analisar os comportamentos dos docentes estrangeiros da UFC em relação à Autogestão de Carreira, integrando-os às principais razões que os levaram à migração para o exterior.

Os seguintes objetivos específicos foram propostos: (1) verificar quais são os principais Comportamentos de Posicionamento adotados pelos docentes estrangeiros da UFC; (2) descrever os principais Comportamentos de Influência adotados pelos docentes estrangeiros da UFC; e (3) examinar a Gestão dos Limites Trabalho-Vida Pessoal (família, vida social, outros interesses extratrabalho) praticados pelos docentes estrangeiros da UFC.

São, portanto, os seguintes aspectos desta pesquisa: (a) a Autogestão de Carreira é uma temática que merece maior aprofundamento por parte da academia, tanto por estar relacionada a aspectos como adaptabilidade e empregabilidade quanto por funcionar como uma espécie de auxílio parar nortear as decisões de carreira aos trabalhadores; (b) a necessidade de maior inserção da UFC na realidade internacional de pesquisa é o motor das discussões e políticas institucionais (UFC, 2016); (c) a UFC goza da exceção constitucional para a admissão de estrangeiros por meio de concurso público (artigo 207 da Constituição Federal de 1988); (d) a pesquisa atinente à Autogestão de Carreira de docentes estrangeiros da UFC pode trazer insights para a adoção de medidas que atraiam mais pesquisadores internacionais para essa instituição; (e) o número muito reduzido de publicações que abordem o assunto "docentes estrangeiros" no Brasil (BA et al., 2015) e no mundo (Selmer; Lauring, 2011); e (f) a visão dos docentes estrangeiros da UFC (32 efetivos e sete visitantes) sobre como ocorrem suas decisões de carreira poderá contribuir para medidas que eventualmente induzam a um maior comprometimento por parte deles.

\section{Metodologia}

Considerando os objetivos específicos desta investigação, o estudo da temática da autogestão dos docentes estrangeiros demandava um levantamento empírico e pesquisa bibliográfica, tendo-se utilizado também a técnica de entrevista como forma de alcançar respostas e esclarecimentos sobre o fenômeno social estudado. Assim, a estratégia de pesquisa escolhida foi o estudo de caso (Gray, 2012), com base em uma perquirição de caráter qualitativo (Sampieri; Collado; Lucio, 2013) e descritivo.

A pesquisa qualitativa envolve a coleta direta de dados, sendo preferencialmente descritiva. Nas ciências sociais a entrevista é uma das técnicas mais utilizada, pois permite a observação, captação, interpretação, análise de dados e informações, dando ao pesquisador argumentos para o desenvolvimento do trabalho (Pereira et al, 2018).

O estudo de caso foi escolhido como método para o desenvolvimento deste trabalho por permitir amplo conhecimento do objeto estudado, o qual vem sendo utilizado com frequência em pesquisas sociais, haja vista que permite explorar situações da vida real que não estão bem delimitadas (Gil, 2008). Para Yin (2005 apud Gil, 2008, p. 58), o estudo de caso “[...] é um estudo empírico que investiga um fenômeno atual dentro do seu contexto de realidade, quando as fronteiras entre o fenômeno e o contexto não são claramente definidas".

Os dados primários foram coletados por meio de entrevista semiestruturada, a qual continha 15 perguntas sociodemográficas, 15 perguntas relacionadas às teorias de suporte da pesquisa e quatro perguntas sobre aspectos gerais da UFC. A análise de dados foi conduzida adotando-se a técnica de análise de conteúdo, utilizando-se o suporte do software Atlas TI.

A UFC tem em seu quadro 52 docentes estrangeiros efetivos não naturalizados (UFC, 2018), o que perfaz cerca de 4,5\% do total geral de docentes da instituição. A exemplo da pesquisa de Richardson e McKenna (2002), considerou-se importante avaliar o vínculo dos pesquisados - os quais não poderiam estar em uma situação provisória, mas efetiva. Também contextualizando para a realidade brasileira, presume-se que os servidores efetivados se sentirão mais à vontade para emitir 
opiniões sinceras, dessa maneira, professores visitantes, substitutos e efetivos que não tivessem terminado o estágio probatório até o dia 4 de junho de 2018 foram excluídos desta pesquisa.

Tendo em vista que também foi considerado o limite de dez anos de trabalho na organização, segundo a pesquisa de Richardson e McKenna (2002), o grupo selecionado de docentes estrangeiros constou de 21 professores. Todos foram, então, convidados via e-mail para participarem da pesquisa, porém somente 13 se dispuseram a ser entrevistados.

Os países de origem dos 13 docentes entrevistados são Alemanha, Argentina, Chile, Colômbia, França, Itália, Polônia, Portugal e Romênia. Foram entrevistados oito homens e cinco mulheres. A faixa etária variou de 38 a 56 anos, sendo a grande maioria casada (nove docentes casados, três solteiros e um divorciado).

$\mathrm{Na}$ trajetória prévia, antes de ingressarem nos quadros efetivos da UFC, somente um docente havia cursado pósgraduação nessa instituição, e quase todos (com exceção de um) haviam tido experiências anteriores na área de docência. Praticamente $50 \%$ dos entrevistados (sete) estão atualmente no exercício oficial de cargos acadêmico-administrativos (coordenações de cursos da graduação, pós-graduação, chefia de secretarias etc.) nos centros, faculdades e institutos onde estão lotados. Esse dado pode indicar o nível de integração desses docentes nas equipes em que atuam.

Todos os professores estão na categoria de adjunto. Houve uma expressiva diversidade em termos de área de conhecimento: os profissionais entrevistados atuam nas Ciências Biológicas, Ciências Exatas e da Terra, Ciências Humanas, Ciências Sociais Aplicadas, Engenharias e Linguística, Letras e Artes, de acordo com a classificação de áreas de conhecimento do Conselho Nacional de Desenvolvimento Científico e Tecnológico (CNPq, 2018).

Visando à teoria selecionada e aos objetivos específicos da pesquisa, foram tomadas quatro categorias: razões de escolha de trabalho na UFC; Comportamentos de Posicionamento; Comportamentos de Influência; e Gestão de Limites Trabalho-Vida Pessoal. Com apoio dessas categorias, foram definidas as respectivas unidades de contexto e as unidades de registro, conforme pode ser visto no Quadro 1.

Quadro 1 - Categorias, unidades de contexto e unidades de registro.

\begin{tabular}{|c|c|c|}
\hline $\begin{array}{l}\text { Categorias de } \\
\text { análise }\end{array}$ & Unidades de contexto & Unidades de registro \\
\hline \multirow{7}{*}{$\begin{array}{l}\text { Comportamentos de } \\
\text { Posicionamento }\end{array}$} & \multirow{2}{*}{$\begin{array}{l}\text { Oportunidade } \\
\text { estratégica de } \\
\text { mobilidade }\end{array}$} & Possibilidade de contribuir para o departamento \\
\hline & & Possibilidade de conhecer mais da dinâmica administrativa \\
\hline & \multirow[b]{2}{*}{$\begin{array}{l}\text { Investimento em } \\
\text { capital humano }\end{array}$} & Realização de cursos de capacitação/qualificação \\
\hline & & $\begin{array}{l}\text { Participação em eventos científicos } \\
\text { (conferências, congressos, etc.) }\end{array}$ \\
\hline & $\begin{array}{l}\text { Desenvolvimento de } \\
\text { rede de contatos }\end{array}$ & Participação em eventos visando a contatos \\
\hline & \multirow{2}{*}{$\begin{array}{l}\text { Inovação do conteúdo } \\
\text { do trabalho }\end{array}$} & Realização de atividades de aprimoramento na didática \\
\hline & & $\begin{array}{l}\begin{array}{l}\text { Realização de pesquisas na área de atuação e em áreas } \\
\text { correlatas }\end{array}\end{array}$ \\
\hline $\begin{array}{l}\text { Comportamentos de } \\
\text { Influência }\end{array}$ & Autopromoção & $\begin{array}{l}\text { Busca de oportunidades para maior visibilidade de suas } \\
\text { conquistas }\end{array}$ \\
\hline
\end{tabular}




\begin{tabular}{|c|c|c|}
\hline & Bajulação & $\begin{array}{c}\text { Esforço para prestigiar chefias ou pessoas com autoridade } \\
\text { ostensivamente }\end{array}$ \\
\cline { 2 - 3 } & Influência ascendente & Defesa objetiva de méritos pessoais \\
\hline $\begin{array}{c}\text { Gestão de Limites } \\
\text { Trabalho-Vida } \\
\text { Pessoal }\end{array}$ & $\begin{array}{c}\text { Manutenção das } \\
\text { fronteiras }\end{array}$ & Papéis de transição \\
\cline { 2 - 3 } & & $\begin{array}{c}\text { Realização de atividades de um domínio em outro } \\
\text { eventualmente }\end{array}$ \\
\hline
\end{tabular}

Fonte: Adaptado de Canholi Júnior (2015).

No total, foram realizadas 15 entrevistas, porém, em razão dos critérios expostos anteriormente e das respostas lacônicas de um dos respondentes, consideraram-se 13 entrevistas ao final. Uma entrevista aconteceu entre 10 e 16 de agosto de 2017 e as demais, no período de $1^{\circ}$ de junho a 24 de julho de 2018. As entrevistas seguiram um protocolo metodológico, conforme recomendado por Creswell (2010).

Quanto à coleta de dados, foi adotada a triangulação de fontes de pesquisa, que representa "[...] a visão de vários informantes e o emprego de uma variedade de técnicas de coleta de dados que acompanha o trabalho de investigação" (Minayo, 2010, p. 70). Foram, assim, consultados documentos oficiais e práticas organizacionais adotadas pela UFC, além da realização das entrevistas em si. Por sua vertente fenomenológica (Collis; Russey, 2005), a entrevista semiestruturada é expressa como a melhor opção para ser adotada nesta pesquisa, pois, dentre outros fatores, busca um entendimento aprofundado da realidade dos respondentes.

\section{Resultados e Discussão}

O papel das universidades, como recurso para contribuir para o desenvolvimento, requer atenção para os docentes diplomados em universidades estrangeiras que entram no mercado. É preciso haver um ajuste para as questões locais, regionais e internacionais, numa construção de processos cooperativos para o desenvolvimento (Borba et al., 2020).

Vários autores (Alencar; Fleith, 2010; Borsoi, 2012; Farias, 2010; Lima; Lima-Filho, 2009) alertam sobre o contexto complexo em que a carreira docente está inserida. As pressões por produtividade acadêmica em um contexto com recursos limitados atestam que "[...] as perspectivas produtivista e competitiva, próprias do mundo globalizado do trabalho, invadiram o mundo acadêmico" (Borsoi, 2012, p. 90).

Constitui-se, então, para o docente estrangeiro um grande desafio elaborar suas escolhas estratégicas de carreira ante essa realidade. Tendo em vista a metodologia da análise de conteúdo, os Comportamentos de Posicionamento e de Influência e a Gestão de Limites Trabalho-Vida Pessoal foram considerados como categorias de análise. A cada categoria de análise estão agregadas unidades de contexto, e as unidades de contexto estão relacionadas às unidades de registro.

No caso dos Comportamentos de Posicionamento, as unidades de contexto oportunidade estratégica de mobilidade, investimento em capital humano, desenvolvimento de rede de contatos e inovação do conteúdo do trabalho foram todas pontuadas nos relatos dos docentes estrangeiros. Os professores consideram enriquecedoras as experiências na gestão de seus departamentos/coordenações, criam ou se inserem em grupos de pesquisa ou extensão e buscam ou aproveitam oportunidades variadas para investimento em capital humano, tais como participação de cursos de capacitação/qualificação e eventos científicos, além de estarem atentos às redes de contatos.

Já em relação aos Comportamentos de Influência, enquanto houve incidência de relatos sobre as unidades de contexto autopromoção e influência ascendente, pode-se considerar a inexistência da unidade de contexto bajulação. Os docentes 
estrangeiros rejeitam o puro exibicionismo, mas estão atentos a oportunidades de maior visibilidade de suas conquistas, porém de um modo mais sofisticado: por meio de publicações de artigos e de menções sutis nas redes sociais sobre suas atividades, dentre outras estratégias.

Na esfera da Gestão de Limites Trabalho-Vida Pessoal, por meio das unidades de contexto manutenção das fronteiras e papéis de transição, pode-se perceber que os docentes estrangeiros consideram uma grande vantagem de suas profissões o grau de autonomia para gerir o trabalho em função das questões pessoais, contudo, em sua maioria, relatam dificuldades em separar as atividades do domínio de trabalho daquelas exercidas no domínio da vida privada.

Em virtude da natureza específica da carreira docente em uma Instituição Federal de Ensino Superior (IFES), em função da estabilidade no trabalho, dentre outras características, os Comportamentos de Influência não foram pontuados significativamente, enquanto os Comportamentos de Posicionamento e a Gestão de Limites Trabalho-Vida Pessoal foram mais abordados nas respostas das entrevistas.

Para melhor ilustrar, segue abaixo o Quadro 2 que ilustra as análises realizadas nos parágrafos anteriores.

Quadro 2 - Relatos dos professores durante as entrevistas.

\begin{tabular}{|c|c|}
\hline \multirow{3}{*}{$\begin{array}{l}\text { Comportamentos de } \\
\text { Posicionamento }\end{array}$} & $\begin{array}{c}\text { "porque acredito muito nessa direção que o Departamento está indo de } \\
\text { crescer, de tentar sempre trazer... sempre primeiro formar pessoas boas, e } \\
\text {... ehhh... produzir pesquisa de boa qualidade" }\end{array}$ \\
\hline & $\begin{array}{c}\text { “...sempre realmente eu gostei, desde da graduação, eu gostei da área de } \\
\text { pesquisa, né, e também da vida acadêmica, de forma geral. Quando eu } \\
\text { terminei o mestrado ainda passei em alguns concursos, né, mas eu optei por } \\
\text { fazer doutorado" }\end{array}$ \\
\hline & “...o curso de didática que eu fiz aqui foi muito enriquecedor também” \\
\hline \multirow{3}{*}{$\begin{array}{l}\text { Comportamentos de } \\
\text { Influência }\end{array}$} & $\begin{array}{c}\text { "...observaram e assim perceberam que eu era um professor comprometido com a } \\
\text { Universidade, com uma boa produção, com uma boa avaliação dos alunos na } \\
\text { didática, eles se abriram mais" }\end{array}$ \\
\hline & $\begin{array}{c}\text { "Nunca vi alguém se exibir, apresentando seus títulos, até na verdade pelo } \\
\text { contrário, às vezes a gente gostaria de conhecer mais informações sobre } \\
\text { os colegas e não tem...uma exposição mais ativa nas mídias em outros } \\
\text { espaços eu acho que isso é interessante" }\end{array}$ \\
\hline & $\begin{array}{l}\text { “...nós temos aqui colegas obviamente muito, muito dotados né dentro do } \\
\text { departamento, mas as pessoas não andam ai a mostrar as medalhas né, as } \\
\text { pessoas são mais inteligentes do que isso, } \\
\text { mostrando, mas de outra maneira.” }\end{array}$ \\
\hline \multirow[t]{3}{*}{$\begin{array}{c}\text { Gestão de Limites Trabalho- } \\
\text { Vida Pessoal }\end{array}$} & $\begin{array}{l}\text { "...antes eu tinha mais tempo livre antes de assumir a coordenação. } \\
\text { Agora tenho menos tempo livre, mas não posso dizer estar insatisfeito } \\
\text { porque tô me dedicando muito ao trabalho e estou fazendo coisas que eu } \\
\text { acho interessantes" }\end{array}$ \\
\hline & $\begin{array}{l}\text { “...as aulas a noite pra quem tem filho obrigam } \\
\text { a uma certa logística que não é tão fácil.” }\end{array}$ \\
\hline & $\begin{array}{c}\text { “...eu tenho a minha família e os finais de semana são da minha família e } \\
\text { quando chego em casa também tô com meus filhos, com minha esposa e } \\
\text { esse tempo realmente tenho aproveitado" }\end{array}$ \\
\hline
\end{tabular}

Fonte: Autores (2020). 
Conforme os relatos descritos no Quadro 2, os professores conseguem administrar melhor os comportamentos de influência e de posicionamento, mas a gestão de limites trabalho-vida pessoal apresenta alguma dificuldade, como já era esperado, uma vez que os fatores externos aumentam, como exemplo, os horários das aulas dos filhos e de atividades de lazer.

Conforme pesquisado por Raabe, Frese e Beehr (2007) e por De Vos e Soens (2008), os empregadores de hoje não oferecem mais uma perspectiva de longo prazo para a carreira em suas organizações. Ao contrário, conforme já mencionado, é o próprio empregado que deve estar atento a criar opções que lhe permitam realizar objetivos pessoais de carreira e lhe assegurem assertividade em suas escolhas.

Embora a carreira docente em uma IFES ofereça estabilidade, é percebido que alguns ganhos salariais são obtidos por meio de ocupações de chefias e de bolsas de pesquisa. Nesse contexto, é plausível considerar a argumentação de King (2004), para a qual a autogestão de carreira merece considerável atenção por parte da psicologia vocacional. Segundo Savickas (2011, p.4), a concepção atualizada de psicologia vocacional refere-se à ideia de que "[...] um 'eu' essencial não existe a priori; em vez disso, constituir um 'eu' é um projeto de vida", considerando a autoatualização e a autoconstrução.

Nesse sentido, pôde-se perceber que os docentes estrangeiros "sabem agir" em seu exercício profissional, conforme preconizado por Le Boterf (2000), e desenvolvem atitudes e comportamentos que são a base do conceito de competência (Kuenzer, 2003). Estes acadêmicos são proativos em relação às suas carreiras e, de modo geral, estão satisfeitos com as oportunidades que lhes são oferecidas como docentes de uma IFES brasileira.

Com relação ao atendimento do objetivo geral, foram estipulados quatro objetivos específicos, que foram alcançados mediante a análise de conteúdo das entrevistas transcritas. Assim, foram codificadas as incidências, nas entrevistas, dos Comportamentos de Posicionamento, de Influência e de Gestão de Limites Trabalho-Vida Pessoal.

Quanto ao primeiro objetivo específico, que foi identificar os principais comportamentos de posicionamento adotados pelos docentes estrangeiros da UFC, o destaque foi para o comportamento de inovação do conteúdo do trabalho (engajamento do professor em projetos de pesquisa e em atividades de aprimoramento da didática).

Sobre o segundo objetivo específico, o alvo era descrever os principais Comportamentos de Influência adotados pelos docentes estrangeiros da UFC. Supunha-se que seriam os comportamentos de autopromoção e influência ascendente, e a análise das entrevistas confirmou essa percepção, sendo inexistente as menções sobre bajulação.

No terceiro objetivo específico, que se referiu ao exame da Gestão dos Limites Trabalho-Vida Pessoal (família, vida social, outros interesses extratrabalho) praticados pelos docentes estrangeiros da UFC, verificou-se que, ainda que haja muitas atividades do domínio do trabalho sendo executadas na esfera pessoal, os pesquisados estão satisfeitos com suas decisões particulares em relação a esses limites.

Percebeu-se, por meio da análise das entrevistas, que a esfera familiar tem proeminência nas decisões pertinentes à gestão da carreira, o que demonstra o alto grau de autonomia que os professores estrangeiros, bem como seus colegas brasileiros, têm em relação às escolhas de antecipação ou postergação de defesas de trabalhos acadêmicos, participação ou não de congressos e conferências, etc., conforme relatado pelos docentes, mas essa autonomia tem um preço: para poder dar conta das muitas atribuições concomitantes (ensino, pesquisa, extensão, cargos de gestão), os professores levam muito trabalho para casa, além de estarem atentos aos grupos do WhatsApp e às caixas postais de e-mail. $\mathrm{O}$ trabalho não para em casa.

\section{Conclusão}

O estudo contribuiu para um melhor entendimento das motivações de carreira de docentes estrangeiros no Brasil. Foi possível notar que, de forma geral, as razões que moveram os entrevistados não diferem muito das razões que apresentaria um profissional brasileiro atuando em instituições de nível superior (Bouzada; Kilimnik; Oliveira, 2012). 
Como o estrangeiro, muitas vezes a estabilidade na carreira é uma forte razão para um brasileiro prestar o concurso de professor em uma IFES, o qual, uma vez ingresso, também estará envolvido em muitas atividades de pesquisa e usufruirá das mesmas autonomias e desafios do ambiente universitário atual.

É necessário reconhecer que a pesquisa realizada com este grupo apresenta limitações. Assim sendo, as considerações deste estudo não podem ser generalizadas, pois estão relacionadas com as particularidades da UFC e dos próprios entrevistados. Sugere-se, assim, que pesquisas futuras persistam na investigação a respeito da carreira de acadêmicos estrangeiros, identificando os fatores de atratividade, de permanência na instituição e o grau de contribuição no âmbito acadêmico. Como já se averiguou, essa categoria profissional tem importantes e válidas contribuições para as instituições onde esses docentes estão inseridos e pode fornecer mais pistas para que as IFES sejam mais atrativas para acadêmicos internacionais. Utilizando-se o modelo de Autogestão de Carreira de King (2004), seria útil pesquisar como tem sido a questão dos resultados almejados de carreira, se há maior incidência de satisfação na vida como um todo, se há mais satisfação somente na carreira em si ou se há uma sensação de impotência. Analisar esses aspectos contribuiria para as IFES elaborarem programas que incentivassem reflexões e atitudes em relação ao bem-estar geral de seu quadro efetivo, promovendo iniciativas de retenção de talentos, tanto estrangeiros como brasileiros.

\section{Referências}

Alencar, E. M. L. Soriano de \& Fleith, D. de S. (2010). Criatividade na educação superior: fatores inibidores. Avaliação: Revista da Avaliação do Ensino Superior, Sorocaba, 15(2), 201-206. http://submission.scielo.br/index.php/aval/article/view/27372.

Ba, S. A. Cisse et al. (2015). Perfil socioprofissional do professor estrangeiro na universidade pública brasileira. In: Congresso Ibero-Americano de Investigación Cualitativa, 3. Badajoz. Acatas... Badajoz. 79-92. http://relatec.unex.es/revistas/index.php/campoabierto/article/view/1689/1049.

Borba, P. Cardoso et al. (2020). A universidade e seu papel no desenvolvimento regional: um mapeamento do tema conforme as delimitações postas pelos pesquisadores. Gestão \& Regionalidade, São Caetano do Sul, 36(109), 31-54. https://seer.uscs.edu.br/index.php/revista_gestao/article/view/7381/3151.

Borsoi, I. C. F. (2012). Trabalho e produtivismo: saúde e modo de vida de docentes de instituições públicas de ensino superior. Cadernos de Psicologia Social do Trabalho. São Paulo, 15(1), 81-10. https://www.revistas.usp.br/cpst/article/view/49623/53726.

Bouzada, V. C. P. C.; Kilimnik, Z. M. \& Oliveira, L. C. V. de. (2012). Professor iniciante: desafios e competências da carreira docente de nível superior e inserção no mercado de trabalho. Revista de Carreiras e Pessoas, São Paulo, 2(1), 1-18. https://revistas.pucsp.br/recape/article/view/9336.

Brasil. Constituição de 1988. Constituição da República Federativa do Brasil. Diário Oficial [da] República Federativa do Brasil, Poder Executivo, Brasília, DF, 5 out. 1988. http://www.planalto.gov.br/ccivil_03/constituicao/constituicaocompilado.htm.

Brasil. Decreto $\mathrm{n}^{\circ}$ 7.485, de 18 de maio de 2011. Dispõe sobre a constituição de banco de professor-equivalente das universidades federais vinculadas ao Ministério da Educação e regulamenta a admissão de professor substituto, de que trata o inciso IV do art. $2^{\circ}$ da Lei ${ }^{\circ} 8.745$, de 9 de dezembro de 1993. Diário Oficial [da] República Federativa do Brasil, Poder Executivo, Brasília, DF, 19 maio 2011. http://www.planalto.gov.br/ccivil_03/_ato20112014/2011/decreto/d7485.htm.

Brasil. Lei no 12.772, de 28 de dezembro de 2012. Dispõe sobre a estruturação do Plano de Carreiras e Cargos de Magistério Federal; sobre a Carreira do Magistério Superior, de que trata a Lei n ${ }^{\circ}$ 7.596, de 10 de abril de 1987; sobre o Plano de Carreira e Cargos de Magistério do Ensino Básico, Técnico e Tecnológico e sobre o Plano de Carreiras de Magistério do Ensino Básico Federal, de que trata a Lei n 11.784 , de 22 de setembro de 2008; sobre a contratação de professores substitutos, visitantes e estrangeiros, de que trata a Lei n ${ }^{\circ} 8.745$ de 9 de dezembro de 1993; sobre a remuneração das Carreiras e Planos Especiais do Instituto Nacional de Estudos e Pesquisas Educacionais Anísio Teixeira e do Fundo Nacional de Desenvolvimento da Educação, de que trata a Lei n ${ }^{\circ}$ 11.357, de 19 de outubro de 2006; altera remuneração do Plano de Cargos Técnico-Administrativos em Educação; altera as Leis n ${ }^{\text {s }}$ 8.745, de 9 de dezembro de 1993, 11.784, de 22 de setembro de 2008, 11.091 , de 12 de janeiro de 2005, 11.892, de 29 de dezembro de 2008 , 11.357 , de 19 de outubro de 2006, 11.344, de 8 de setembro de 2006, 12.702, de 7 de agosto de 2012, e 8.168, de 16 de janeiro de 1991 ; revoga o art. $4^{\circ}$ da Lei $\mathrm{n}^{\circ} 12.677$, de 25 de junho de 2012; e dá outras providências. Diário Oficial [da] República Federativa do Brasil, Poder Executivo, Brasília, DF, 31 dez. 2012. http://www.planalto.gov.br/ccivil_03/_ato2011-2014/2012/lei/112772.htm.

Canholi Júnior, C. (2015) Os sentidos do trabalho para os trabalhadores do saneamento básico. 126 f. Dissertação (Mestrado em Administração e Controladoria) - Programa de Pós-Graduação em Administração e Controladoria, Universidade Federal do Ceará, Fortaleza. http://www.repositorio.ufc.br/bitstream/riufc/27111/1/2015_dis_ccanholijunior.pdf.

Collis, J. \& Hussey, R. (2005). Pesquisa em Administração: um guia prático para alunos de graduação e pós-graduação. (2a ed.), Bookman.

CNPQ - Conselho Nacional de Desenvolvimento Científico e Tecnológico. Tabela de Áreas do Conhecimento. 2018. http://www.cnpq.br/documents/10157/186158/tabeladeareasdoconhecimento.pdf. 
De Vos, Ans \& Soens, Nele. (2008). Protean attitude and career success: the mediating role of self-management. Journal of Vocational Behavior, 73(3), 449456, 2008. http://www.sciencedirect.com/science/article/pii/s0001879108000754.

Farias, L. de M. (2010). O trabalho docente nas instituições públicas de ensino superior: intensificação do produtivismo acadêmico na UFPA. $203 \mathrm{f}$. Dissertação (Mestrado em Educação) - Programa de Pós-Graduação em Educação, Universidade Federal do Pará, Belém, 2010. http://www.repositorio.ufpa.br/jspui/bitstream/2011/2740/1/dissertacao_trabalhodocenteinstituicoes.pdf.

Farina, M. C. \& Penof, D. G. (2020). Ações de interdisciplinaridade na educação superior: uma avaliação com base na análise de redes sociais. Gestão \& Regionalidade, São Caetano do Sul, 36(107), 128-153, 2020. https://seer.uscs.edu.br/index.php/revista_gestao/article/view/5706/2866.

Fraser, K. \& Hvolby, H.-H. (2010). Effective teamworking: can functional flexibility act as an enhancing factor? An Australian case study. International Journal of Manpower, 16(1/2), https://doi.org/10.1108/13527591011028933. https://www.researchgate.net/publication/242344668_effective_teamworking_can_functional_flexibility_act_as_an_enhancing_factor_an_australian_case_stu dy.

Gil, A. Carlos (2008). Métodos e técnicas de pesquisa social. (6a ed.), Atlas.

Gray, D. E. (2012). Pesquisa no mundo real. (2a ed.), Penso.

King, Z. (2004). Career self-management: Its nature, causes and consequences. Journal of Vocational Behavior, 65, 112-133, https://www.researchgate.net/publication/222573015_career_self-anagement_its_nature_causes_and_consequences_journal_of_vocational_behavior_65_112133.

Kuenzer, A. Z. (2003). Competência como práxis: os dilemas da relação entre teoria e prática na educação dos trabalhadores. Boletim Técnico do Senac, Rio de Janeiro, 29(1), 28-41. http://servicos.educacao.rs.gov.br/dados/seminariointernacional/acacia_kuenzer_competencia_praxis.pdf.

Le Boterf, G. (2000). La mise en place d'une démarche compétence: quelques conditions de réussite. Personnel, n. 412, p. 35-43. http://www.guyleboterfconseil.com/images/andcp.pdf.

Lima, M. de F. E. M. \& Lima-Filho, D. de O. (2009). Condições de trabalho e saúde do/a professor/a universitário/a. Ciências \& Cognição, Rio de Janeiro, 14(3), 62-82. http://cienciasecognicao.org/revista/index.php/cec/article/view/253/136

Luna, I. N. (2012). Empreendedorismo e orientação profissional no contexto das transformações do mundo do trabalho. Revista Brasileira de Orientação Profissional, Campinas, 13(1), 111-116. http://pepsic.bvsalud.org/pdf/rbop/v13n1/12.pdf.

Minayo, M. C. de S. (2010). Introdução. In: MINAYO, Maria Cecília de Souza; ASSIS, Simone Gonçalves de; SOUZA, Edinilsa Ramos de (Org.). Avaliação por triangulação de métodos: abordagem de programas sociais. Rio de Janeiro: Fiocruz. p. 15-51.

Newstrom, John W. (2008). Comportamento organizacional: o comportamento humano no trabalho. Tradução: Ivan Pedro Ferreira Santos. São Paulo: McGraw-Hill

Organização das Nações Unidas Para a Educação, Ciência e Cultura. Instituto Internacional para a Educação Superior na América Latina e no Caribe IESALC. A educação superior no Brasil. Porto Alegre, 336 p., nov. 2002. http://flacso.redelivre.org.br/files/2013/03/1109.pdf>.

Pereira, A. S. et al. (2018). Metodologia da pesquisa científica. UFSM.

Raabe, B.; Frese, M. \& Beehr, T. A. (2007). Action regulation theory and career self-management. Journal of Vocational Behaviour, (70), 297-311. http://www.sciencedirect.com/science/article/pii/s000187910600114x.

Richardson, J. \& McKenna, S. (2002). Leaving and experiencing: why academics expatriate and how they experience expatriation. Career Development International, 7(2), 67-78. http://www-emeraldinsight-com.ez11.periodicos.capes.gov.br/doi/pdfplus/10.1108/13620430210421614.

Sampieri, R. H.; Collado, C. F. \& Lucio, M. del P. B. (2013). Metodologia de pesquisa. (5a ed.), McGraw-Hill.

Savickas, M. (2011). New questions for vocational psychology: premises, paradigms and practices. Journal of Career Assessment, 19(3), $251-258,2011$. https://journals.sagepub.com.ez11.periodicos.capes.gov.br/doi/pdf/10.1177/1069072710395532.

Schein, E.(2013). Career anchors self-assessment. (4a ed.), John Wiley \& Sons.

Seligmann-Silva, Edith et al. O mundo contemporâneo do trabalho e a saúde mental do trabalhador. Revista Brasileira de Saúde Ocupacional, 35(122), 187191, 2010. http://www.redalyc.org/html/1005/100515726002/.

Selmer, J. \& Lauring, J. (2013). Cognitive and affective reasons to expatriate and work adjustment of expatriate academics. International Journal of Cross Cultural Management, 13(2), 175-191, 2013. http://journals.sagepub.com.ez11.periodicos.capes.gov.br/doi/pdf/10.1177/1470595813485382.

Selmer, J. \& Lauring, J. (2011). Expatriate academics: job factors and work outcomes. International Journal of Manpower, 32(2), 194-210. http://wwwemeraldinsight-com.ez11.periodicos.capes.gov.br/doi/pdfplus/10.1108/01437721111130206.

UFC - Universidade Federal do Ceará. I Seminário de Gestão em Internacionalização e Inovação Tecnológica ocorre hoje (10). Portal da UFC, Fortaleza, 3 nov. 2016. http://www.ufc.br/noticias/noticias-de-2016/9007-i-seminario-de-gestao-em-internacionalizacao-e-inovacao-tecnologica-ocorre-dia-10.

UFC - Universidade Federal do Ceará. Prof. Almir Bittencourt e Prof. José Soares tomam posse em novas pró-reitorias da UFC. Portal da UFC, Fortaleza, 6 fev. 2017. http://www.ufc.br/noticias/noticias-de-2017/9252-prof-almir-bittencourt-e-prof-jose-soares-tomam-posse-em-novas-pro-reitorias-da-ufc.

UFC - Universidade Federal do Ceará. Concursos e processo seletivo. Site da Pró-Reitoria de Gestão de Pessoas da UFC. http://www.progep.ufc.br/concursos-e-processo-seletivo/>. 
Research, Society and Development, v. 10, n. 2, e26910212401, 2021

(CC BY 4.0) | ISSN 2525-3409 | DOI: http://dx.doi.org/10.33448/rsd-v10i2.12401

Organização das Nações Unidas para a Educação, Ciência e Cultura - UNESCO. Instituto Internacional para a Educação Superior na América Latina e no Caribe - IESALC. A educação superior no Brasil. Porto Alegre, 336 p., nov.2002. http://flacso.redelivre.org.br/files/2013/03/1109.pdf>.

Veloso, E. F. R.; Dutra, J. S. \& Nakata, L. E. (2016). Percepção sobre carreiras inteligentes: diferenças entre as gerações y, x e baby boomers. Revista de Gestão, 23,. 88-98. http://www.spell.org.br/documentos/ver/42395/percepcao-sobre-carreiras-inteligentes--diferencas-entre-as-geracoes-y--x-e-baby-boomers. 